\title{
Genetic Transformation for Metabolic Engineering of Tropane Alkaloids
}

\author{
María Alejandra Alvarez and Patricia L. Marconi \\ Institute of Science and Technology Dr. C. Milstein Saladillo 2468, C1440FFX, CABA, \\ Argentina
}

\section{Introduction}

\subsection{Tropane alkaloids: history and relevance}

Historically, plants have been the major source of active compounds for the pharmaceutical industry. Today, plant extracts and its active principles represent $25 \%$ of the annual commercialized drugs in the United States (Kinghorn and Seo, 1996, Buttler 2004, Prakash Rout et al., 2009, Qurishi et al., 2010). Moreover, the World Health Organization has estimated that more than the $80 \%$ of the population in developing countries relies for their health care on traditional medicines mostly from plant origin (Canter et al., 2005). The plant active principles are, in general, a product of the plant secondary metabolism; they are lowmolecular-weight compounds that in general participate in defence mechanisms against diseases (phytoalexins) or as attractants for pollinator insects (pigments and fragrances) (Canter et al., 2005). The production of each group of secondary metabolites, as counterpart of primary metabolites, is in general restricted to a limited number of species, and they usually are organ-specific and furthermore, tissue-specific.

According to their chemical properties, secondary metabolites could be classified in three main groups: a) terpenes, b) phenols and c) alkaloids. Terpenes and terpenoids are the primary constituents of the essential oils, widely used as natural flavour additives for food and fragrances. Phenols are a class of chemical compounds consisting of a hydroxyl group directly bonded to an aromatic hydrocarbon group that seem to be universally distributed in plants. They are essential for the growth and reproduction of plants, and are produced as a response for defending injured plants against pathogens. Finally, alkaloids are characterized for being alkaline nitrogenated organic compounds, derived from aminoacids, generally insoluble in water and soluble in alcohol, ether, chloroform, etc. Among the alkaloids, those derived from tropane have received particular attention for their properties.

\subsection{Tropane alkaloids}

Tropane alkaloids are distributed among the plant families Orchidaceae, Dioscoreaceae, Proteaceae, Rhizophoraceae, Cruciferae, Eritroxilaceae, Euphorbiaceae, Convolvulaceae, Brassicaceae, Olacaceae and Solanaceae. Their principal characteristic is the presence of a pyrrolic ring derived from the ornintine and arginine aminoacids by a chemical reaction catalyzed by ornitin decarboxilase (ODC) and arginin decarboxilase (ADC) respectively (Figure 1). Ornithine and arginine also are the precursors of the polyamines putrescine, espermidine and espermine, which play a critical role in plant development by the regulation of the cell 
division in plants (Theiss et al., 2002). On the other hand, putrescine, by the action of the enzyme putrescine $\mathrm{N}$ - methyltransferase (PMT; EC 2.1.1.53), is sequestered to the secondary metabolism being the first step of the tropane alkaloid biosynthetic pathway.<smiles>N=C(N)NCCC[C@H](N)C(=O)O</smiles>

A<smiles>NCCC[C@H](N)C(=O)O</smiles>
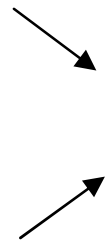

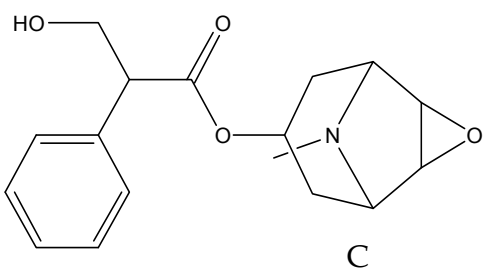

C

Fig. 1. Primary metabolism precursors: arginine (A) and ornitine (B) and the tropane alkaloid final product scopolamine (C).

Hyoscyamine and scopolamine are the end products of the tropane alkaloid biosynthetic pathway having both pharmacological applications for its action in the parasympathetic nervous system. Scopolamine, a 6,7- $\beta$-epoxide of hyoscyamine, is derived from hyoscyamine by the intermediate form 6 -hydroxyhyoscyamine (Fig. 2). The pharmaceutical industry employs hyosciamine, and its racemic form atropine, to obtain hyoscine N-butyl bromide that is used for its antispasmodic action since 1951. This semisynthetic derivative has pharmacological proprieties similar to those from scopolamine but with less activity and more adverse effects (Tytgat, 2007). Figure 2 compares the industrial process for producing the atropine racemic form of hyosciamine, and the scopolamine biosynthetic pathway in plants.

\subsubsection{Scopolamine}

Scopolamine is one of the earlier alkaloids purified from plant sources, described by Albert Ladenburg in 1880. It is the most valuable of the tropane alkaloids being its worldwide demand 10-fold the demand of the sum of hyosciamine (its precursor) and atropine (the semisynthetic drug) (Moyano et al., 2003). As atropine, scopolamine is an anticholinergic drug, besides it also has anti-muscarinic activity. Anticholinergic drugs are, in general, competitive and reversible inhibitors from acetylcholine with effects at parasympathetic level. Because of that pharmacological activity scopolamine has a number of uses in medicine. Its primary use is for the therapy of nausea (transdermal patchs), motion sickness and intestinal cramping. Also, it is used for ophtalmic purposes (to induce mydriasis and cycloplegia) and as a general depressant in combination with narcotic painkillers. It also has secondary uses are a preanesthetic agent, a drying agent for sinuses, lungs and related areas and to reduce motility and secretions in the gastrointestinal tract (tinctures). Uncommonly, it is also used for some forms of Parkinsonism, combined with opioids (e.g.: with morphine). The production and purification of scopolamine is extremely expensive which have made that several groups have focused in finding scopolamine analogs or synthetic forms. 


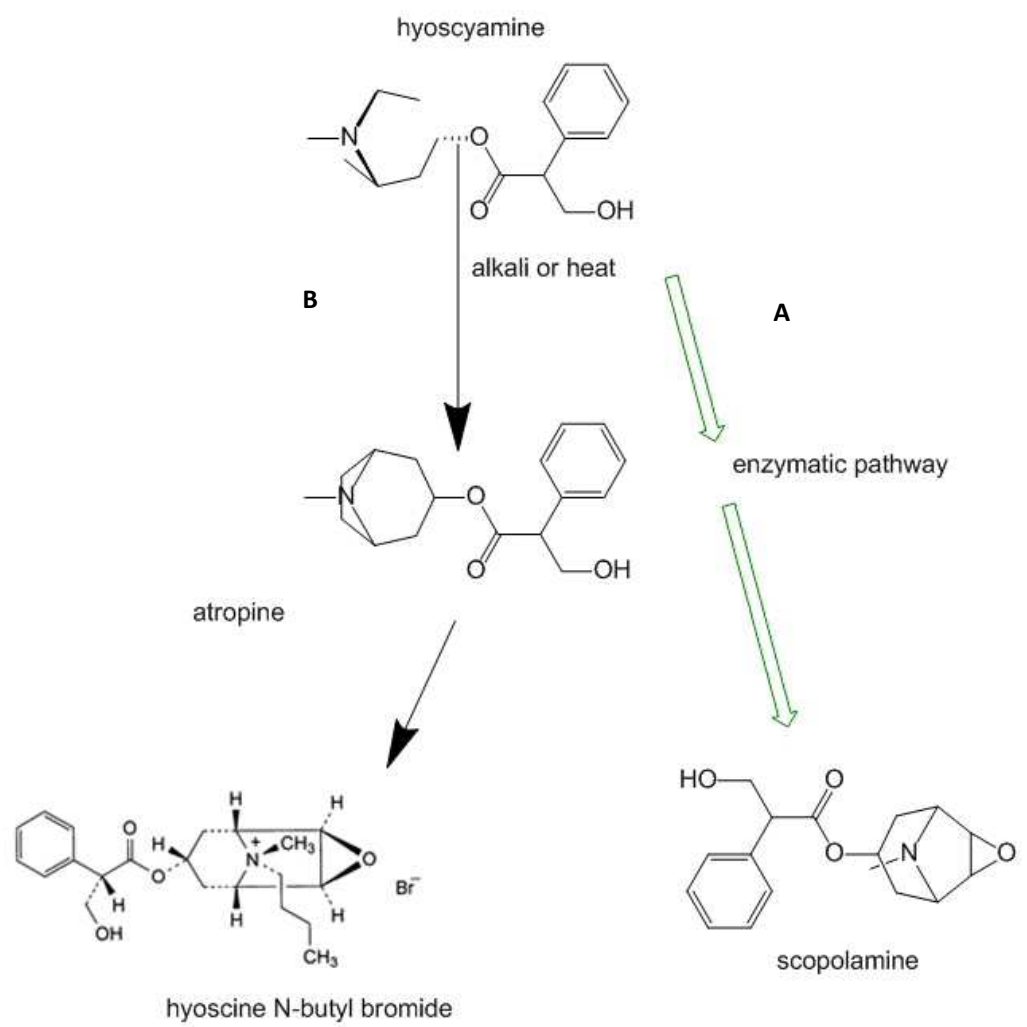

Fig. 2. The racemic hyoscine N-butyl bromide is obtained from natural sources as hyoscyamine (A) or by semi-synthesis from atropine (B). Scopolamine is the final product in the tropane alkaloid pathway being hyoscyamine its precursor.

\subsubsection{Biosynthetic pathway, key points: PMT and $\mathrm{H} 6 \mathrm{H}$}

As was mentioned above, scopolamine and hyoscyamine are the most relevant tropane alkaloids widely in use. Their metabolic pathway starts in putrescine, a polyamine that is shared by several metabolic pathways (e.g.: pyridinic alkaloids). The role of putrescine methyl transferase (PMT; EC 2.1.1.53) is to sequester putrescine from the polyamine pool, which is the cross-point between the primary and secondary metabolism towards the tropane alkaloid pathway. The enzyme PMT catalyses the reaction from putrescine to $\mathrm{N}$ methyl putrescine with S-adenosyl methionine as methyl donor (Zhang et al., 2004, Stenzel et al., 2006). It was described by Mizusaki et al. (1973) in tobacco for the first time, afterwards it has also been described in Hyoscyamus sp. (Hashimoto et al., 1989, Suzuki et al., 1999). The last part of the tropane alkaloid biosynthetic pathway is the enzymatic reaction catalyzed by hyoscyamine-6 $\beta$-hidroxylase $(\mathrm{H} 6 \mathrm{H})$, a 2-oxoglutarate dependent dioxygenase (EC 1.14.11.11, MW: $41.000 \pm 1.0$, optimal pH 7.8) that catalyses the hydroxylation of hyoscyamine to scopolamine in two steps. The first step is the hydroxylation of hyoscyamine to $6 \beta$-hydroxyhyoscyamine, a reaction that requires 2-oxoglutarate, $\mathrm{Fe}^{2+}$, molecular oxygen, and ascorbate. The second step is the epoxidation of the intermediate 
$6 \beta$-hydroxyhyoscyamine producing the 6,7- $\beta$ - hyoscyamine epoxide (scopolamine) (Hashimoto and Yamada, 1986 and 1987).

\section{Strategies for scopolamine production}

The chemical complexity of tropane alkaloids turns almost impossible its substitution by other compounds or the de novo synthesis. To date, alkaloids are extracted from the macerated leaves of wild plants growing in greenhouses. The whole process, performed under Good Manufacture Practices (GMP), makes the final product very expensive thus the search of an alternative production strategy is a priority. The alternative methods comprise biotechnology approaches as the genetic transformation for metabolic engineering to overexpress the key proteins in the biosynthetic pathway and the establishment of in vitro organ, tissue and plant cultures from scopolamine producer species.

\subsection{Metabolic engineering}

The in-depth understanding of biosynthetic pathways, along with the increasing number of cloned genes involved in biosynthesis, enable the exploration of metabolic engineering as a potential effective approach to increase the yield of specific metabolites. It could be achieved by enhancing rate-limiting steps or by blocking competitive pathways. Metabolic engineering is a multidisciplinary powerful tool that uses from bioinformatics, genetics, biochemistry, systems biology, molecular biology, biochemical engineering, etc, for re-direct the metabolic flux generally in order to increase secondary metabolite production yields (e.g.: alkaloids). It also could be useful for a rational and directed modification of metabolic pathways to understand their design and regulation and to study the impact of intermediates and end products in a specific organism.

When the improvement of a productive process is the main goal, the a priori knowledge of the metabolic pathway is fundamental. The next step is to know the kinetic of growth of the biomass that produces the product of interest, the parameters that could reflect that growth, and the election of the parameters that will led to the optimization of the process. Metabolic engineering uses different strategies such as improving the precursors production, redirecting one or more enzymatic reactions in a metabolic pathway, widening the metabolic capacities by stress or increasing the enzymatic activities, etc. Also a reliable strategy is to direct the carbon flux towards the biosynthetic pathway by the overexpression of the genes codifying the limiting enzymes, blocking the feedback inhibition mechanism or the competitive pathways, diminishing catabolism, etc..

\subsubsection{Hairy root culture initiation and maintenance}

Hairy roots are obtained by infection of the plant with different Agrobacterium rhizogenes strains (e.g.: LBA9402 and LBA15834) that harbor the Ri vector (In: Agrobacterium-mediated genetic transformation: history and progress, present book). They are characterized by their indefinite and fast growth and its higher chromosomal stability than in vitro clonal multiplication. The first hairy root cultures were established at the end of the 1980's (Oksman-Caldentey and Strauss, 1986, Hamill et al. 1987, Oksman-Caldentey et al., 1987). Since then, it has been established hairy roots from numerous species, among them scopolamine-producing species (Hyoscyamus, Brugmansia, Duboisia, Atropa, and Scopolia, etc). In general, hairy roots are initiated from axenic plants by infection with A. rhizogenes the hairy root tips usually appear in the infected areas approximately after one week of 
infection, being a chimera between the infected and non-infected cells. Once initiated, they are maintained by transfer to selective media without the addition of plant growth regulators. The hairy root cultures are subcultured in the same medium approximately every 20 days. When the process is performed in liquid medium it is carried on under agitation in an orbital shaker (100 rpm) with $16 \mathrm{~h}$ - photoperiod using cool white fluorescent lamps.

As we have said before, the synthesis of tropane alkaloids is produced in the pericycle of roots (Hashimoto et al., 1991) being the final products translocated to the aerial part of the plant. It is not surprising then that the establishment of hairy roots was considered as an alternative strategy for scopolamine production (Oksman-Caldentey et al., 1991, OksmanCaldentey and Arroo, 2000, Palazón et al., 2003 and 2008). It was reported that Datura stramonium hairy roots de-differentiated and loose their ability to synthesize scopolamine when treated with auxines (Palazón et al., 1995). On the other hand, undifferentiated cultures (calli) do not produce scopolamine proving the need of some degree of tissue specialization (Moyano et al., 1999; Jouhikainen et al., 1999). Evidently, the tropane alkaloid synthesis requires root organization when scopolamine is the end product.

Even though hairy roots are scopolamine producers the yields achieved are low, which has fostered the quest of an alternative production strategy. In the 1990's the first studies about the influence of plant growth regulators on scopolamine yields were performed. The effect of the addition of $\mathrm{GA}_{7}$ on kinetics of growth and alkaloid accumulation in two different Brugmansia candida hairy root clones have demonstrated that $\mathrm{GA}_{7}\left(10^{-4}\right.$ to $\left.10^{-1} \mathrm{mg}^{-1} \mathrm{l}^{-1}\right)$ increased the scopolamine/hyoscyamine ratios in the early phases of growth, the sum of scopolamine plus hyoscyamine per flask decreased during the same growth period. Indeed the addition of $\mathrm{GA}_{3}$ produced higher growth rates but lower alkaloid concentration (Pitta Alvarez \& Giulietti, 1997).

\subsubsection{Elicitation}

The term elicitor was first introduced to describe the action of biomolecules able to induce phytoalexin production. In general, elicitors induce defence systems and increase the resistance to pathogens in plants. Also, pathogens biomolecules derived from the pathogen cell wall (exogenous elicitors), and compounds released from plants by the action of the pathogen, triggers that defence response (Angelova et al., 2006).

At the end of the 1990's several groups started the study of the effect of elicitors on secondary metabolism. Hence, it was evident that biotic elicitors (produced by pathogenic microorganisms or released from their cell walls by plant enzymes) were able to induce changes in secondary metabolites patterns. Also, the release of certain compounds, such as cellulose or pectinase and molecules active in the signal transduction pathway (salicylic acid, jasmonic acid), could also promote the plant defence response (Benhamou, 1996; Guo et al., 1997; Lawrence et al., 2000). That response includes the production of phytoalexins (pathogeneses related proteins), protease inhibitors and a variety of other defence compounds (among them alkaloids). In vitro plant cell cultures have been used for studying the influence of elicitors on secondary metabolism (Zabetakis et al., 1998, Jung et al., 2003, Marconi et al., 2008), and also their influence on tropane alkaloid metabolism particularly in hairy roots (Pitta Alvarez et al., 2000, 2001, Ajungla et al., 2009). Non-conventional elicitors (e.g.: acetate buffer, pectinase, Hormonema sp. homogenate), increased intracellular hyoscyamine content (200-300\%), and the release of scopolamine (up to $1500 \%$ ) and hyosciamine (up to $1100 \%$ ) in B. candida hairy roots (Pitta-Alvarez et al., 2003). Thus, elicitors 
represent a promising and inexpensive alternative to increase production of hyoscyamine and scopolamine by in vitro culture.

\section{Metabolic and genetic engineering}

Molecular biology, as a tool for DNA manipulation, could be used for engineering metabolic pathways. Figure 3 shows the usual strategies employed for overproducing a specific metabolite $(C)$.

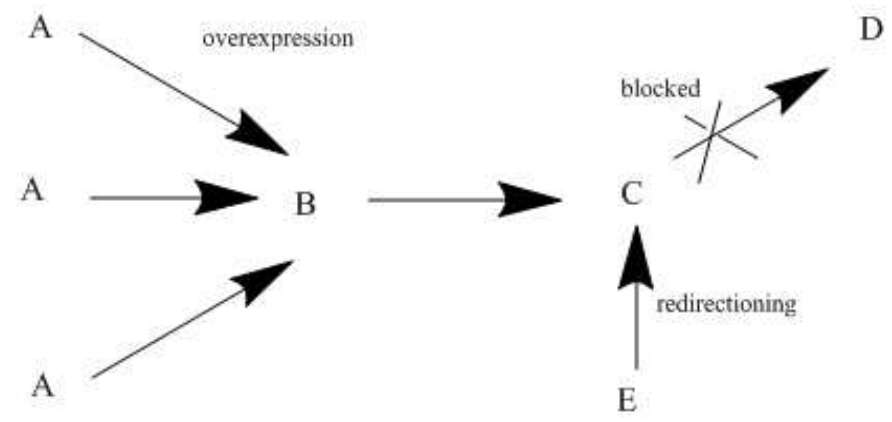

Fig. 3. Strategies for increasing secondary metabolite production by engineering metabolism.

The strategies metabolic engineering uses to increase secondary metabolite production are a) the overexpression of secondary metabolite precursors (A); b) the overexpression of genes whose products are rate-limiting (B), c) the creation of new branches in the biosynthetic pathway (E to $C), d$ ) the blocking of reactions ( $C$ to $D)$ redirecting them to the $C$ pathway, among others. Also, there are other strategies for overproducing $C$ such as a) manipulation of regulatory genes, b) a positive or negative regulation of gene expression, c) selection of mutants with increased expression of metabolites, d) use of specific promoters for tissue/organ specific expression, e) iRNA technology and gene silencing. Each of the strategies above mentioned has unpredictable consequences in the cell homeostasis.

\subsection{Overexpression of key enzymes}

Overexpression of a key enzyme in the biosynthetic pathway is one of the strategies used to increase secondary metabolite production. In general, the overexpressed enzyme catalyzes a bottleneck step. In the tropane alkaloid pathway the key enzyme is $\mathrm{H} 6 \mathrm{H}$. As was mentioned above, $\mathrm{H} 6 \mathrm{H}$ catalyzes two reactions, the hydroxylation at position 6 , rendering an intermediate $6 \beta$-hydroxyhyoscyamine; and the epoxidation that leads to the end product scopolamine. Therefore, overexpression of $\mathrm{H6H}$ is an attractive strategy for poor scopolamine producing species with hyoscyamin-rich accumulation. In vitro shoot and callus cultures shown very low concentration of $\mathrm{H} 6 \mathrm{H}$ and, hence, scopolamine production. On the contrary, hairy root cultures from scopolamine-producing species have high concentration of $\mathrm{H6H}$. The difference in the expression of this enzyme could be attributed to the specialization of root pericycle for producing $\mathrm{H} 6 \mathrm{H}$. Several attempts were made in order to isolate and overexpress the $\mathrm{H} 6 \mathrm{H}$ cDNA in hairy roots for scopolamine production. The h6h cDNA was isolated from B. candida, H. muticus, A. belladonna, Duboisia hybrid with high producing scopolamine capacity (Matsuda et al., 1991, Jouhikainen et al., 1999, Cardillo et 
al., 2005; Canter et al., 2005, Oksman-Caldentey et al., 2007, Palazón et al., 2008). All the isolated sequences reveled high homology $(>80 \%)$. A strategy used is to introduce in lowproducing scopolamine species numerous copies of their own $\mathrm{H6H}$ gene. All the protocols have several common steps. First, the $h 6 h \mathrm{cDNA}$ is cloned into the binary vector and amplified in Escherichia coli. Then, A. rhizogenes is transformed with the binary vector obtained and used for re-introducing, by agrotransformation, that $h 6 h$ cDNA into the genome of the same species from which it was isolated. However, the results were not successful because the $\mathrm{H} 6 \mathrm{H}$ overexpressing clones obtained did not have a significant increase on alkaloid production. Those results could be attributed to an upstream regulation of alkaloid biosynthesis, to a rate limiting speed of $\mathrm{H} 6 \mathrm{H}$ or to a deficiency of precursors.

Another strategy focus on the lack of substrates in the tropane alkaloid pathway. Thus, the carbon flux is redirect from the primary to the secondary metabolism, being PMT the key and pivot enzyme between both metabolisms. There is a strong expression of the pmt gene in the pericycle of Atropa belladona roots that is suppressed by the addition of exogenous auxins (Suzuki et al., 1999, Hibi et al., 1994, Palazón et al., 1995). There are several protocols describing the establishment of PMT overexpressing hairy roots. Nevertheless the results obtained are as disappointing as those obtained overexpressing $\mathrm{H} 6 \mathrm{H}$. The first report of PMT overexpression in hairy roots was with Hyoscyamus albus (Hashimoto et al., 1989). Tracer-feeding studies with radioactive aminoacids demonstrated that putrescine is the precursor of tropane alkaloids. Sato et al. (2000) have reported the overexpression of PMT in Atropa belladonna hairy roots revealing an increase in polyamines pools. However, the alkaloid profile remained unchangeable. On the other hand, the overexpression of PMT from Nicotiana tabacum in Duboisia hybrid hairy roots (yielding scopolamine) produced an increase of pmt gene expression that is not reflected in the alkaloid production (Moyano et al. 2000). Also, there are reports of heterologous tests with non-tropane alkaloid producing species such as Solanum tuberosum (Stenzel et al., 2006) and Nicotiana sylvestris (Sato et al., 2001). The overexpression of PMT in N. sylvestris increasead the nicotine concentration, probably for a higher metabolic flux towards the tropane and pyridinic alkaloid pathways. However, when the pmt gene was overexpressed in the tropane alkaloid producer $A$. belladonna (Sato el al., 2001) and the Duboisia hybrid (Moyano et al., 2002), no significant increase in scopolamine was observed suggesting that methylputrescine is not the rate limiting substrate in the tropane alkaloid pathway.

The overexpression of only one enzyme in a complex metabolic net could not be sufficient to increase some secondary metabolite expression. Particularly, there are several works about the overexpression of more than one of the enzymes involved in the alkaloid tropane pathway (Zhang et al., 2004, Liu et al., 2010, Chunxian et al., 2011). However, not significant scopolamine yields were attained. The unsuccessful results could be attributed to the transgenic transformation processes itself. The mechanism of integration of transgenes into plant DNA is poorly understood, the integration of many genes at one or a few loci could not happen by chance. Also, multiple copies of one or more transgenes can result in postranscriptional gene silencing and turn unstable and reduce gene expression (Matzke \& Matzke; 1998; Palazón et al., 1998; Bulgakov et al., 2004; Kutty et al., 2011). Evidently, h6h played a more important role in stimulating scopolamine accumulation than pmt. Nevertheless, when pmt redirects the carbon flux to the tropane pathway and $h 6 h$ is overexpressed there is an accumulation of scopolamine (Zhang et al. 2004).

The genetic transformation with numerous in-tandem genes could be troublesome. For hairy root induction and $p m t$ and $h 6 h \mathrm{cDNA}$ insertion, at least three tandem transformations 


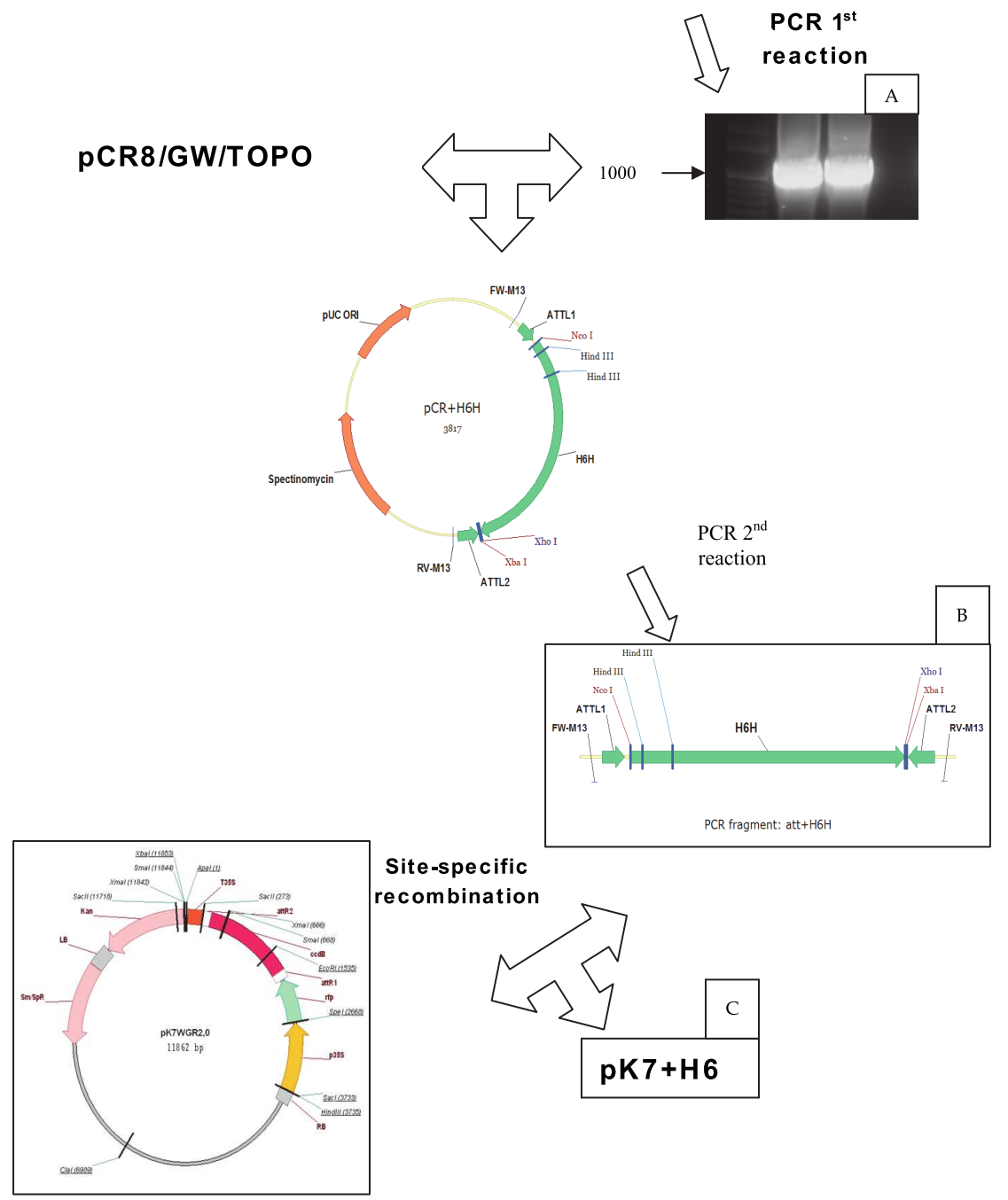

Fig. 4. Scheme of the site-specific recombination between the PCR product harboring pmt or $h 6 h \mathrm{cDNA}$ and the binary vector. During the first PCR round (PCR 1st Reaction), the H6H (or PMT) cDNA is isolated and purified from an agarose gel electrophoresis (A). The PCR fragment is inserted between the specific attachment sites sequences (att sites) into the Entry $\mathrm{pCR} 8 / \mathrm{FW} / \mathrm{TOPO}$ vector producing the plasmid $\mathrm{pCR}+\mathrm{H} 6 \mathrm{H}(\mathrm{B})$. The second round of PCR (PCR 2nd Reaction) is carried out with the M13 forward and reverse primers in order to amplify a cDNA fragment encoding the sequence of interest flanked by the att left and right recombination sequences. These sequences permit the site-specific recombination between the extended PCR fragments and a Destination binary plasmid (pK7WG2.00) following the Gateway protocol. LR Clonase II enzyme MIX is used to catalyze the site specific recombination reaction which is performed according to the manufacturer's protocol (Invitrogen). The final product is the binary destination vector $\mathrm{pK} 7+\mathrm{H} 6 \mathrm{H}(\mathrm{C})$. 
are needed. New and simple DNA transfer methods simplify the process as, for example, the Gateway system ${ }^{\circledR}$, based on bacteriophague Lambda site-specific recombination system (Karimi et al., 2002; Attanasov et al., 2009; Dubin et al., 2008, Xu \& Quinn, 2008). Figure 4 shows a protocol designed in our lab for the production of a PCR fragment for $h 6 h \mathrm{cDNA}$ ready to recombine into the destination vector independently of the antibiotic gene resistance.

\section{New approaches}

In this chapter, we have reviewed some of the most relevant strategies for improving tropane alkaloid biosynthesis such as the establishment of scopolamine overproducing organ cultures, the elicitation and the genetic transformation with homologous genes. Nevertheless, the knowledge generated and the strategies in use have demonstrated that the tropane alkaloid metabolism is immersed into a complex net of metabolic pathways with a delicate equilibrium quite difficult to be manipulated. Modern system biology tools, like elicitation and overexpression, allow the carbon flux redirection with some limitations. These margins cannot be overcome and decelerate the development of a competitive and sustainable production platform. Those troubles and limitations have fostered new strategies based on functional genomics (Goossens et al., 2002; Goossens \& Rischer, 2007, Oksman-Caldentey \& Inzé, 2004) such as biotransformation.

Biotransformation is one of those new strategies. The production of scopolamine and other alkaloids was studied in engineered $N$. tabacum hairy roots overexpressing the $h 6 h \mathrm{cDNA}$ after feeding the cultures with exogenous hyoscyamine (Hakkinen et al., 2005). The results obtained have shown an efficient uptake of hyoscyamine from the culture medium and a higher rate of bioconversion of hyoscyamine to scopolamine (up to $85 \%$ of the total scopolamine being released to the culture medium). Moreover, it was also evident an enhanced production of various nicotine alkaloids suggesting that the regulation of the alkaloid production is probably more complex than presently known.

Another approach was the bioconversion of hyoscyamine to scopolamine using recombinant Saccharomyces cerevisiae that expresses the $h 6 h \mathrm{cDNA}$ isolated from $B$. candida as a biocatalyzer. Transformed S. cerevisiae CEM PK2 expressing $\mathrm{H6H}$ as heterologous protein was able to grow into yeast base medium supplemented with hyoscyamine. However, the results have shown a low ability of hyoscyamine conversion to scopolamine (Cardillo et al., 2005 and 2008).

\section{Conclusions}

In the last two decades plant biotechnology has made considerable advances in the quest of a scopolamine and other tropane alkaloids productive process. Several groups have explored a wide spectrum of strategies that have led to the exhaustive knowledge of the tropane alkaloid pathway, its limiting steps and some of the regulation pathways. It is evident that genetic transformation is a promissory tool for engineering tropane alkaloid biosynthetic metabolism in order to produce high amounts of scopolamine. Combining genetic transformation and metabolic engineering would be a powerful strategy to re-direct the metabolic flux towards that biosynthetic pathway. It became clear, from the results already published, that the overexpression of pmt gene and/or $h 6 h$ gene not only stimulated the conversion of hyoscyamine to scopolamine, but also the capacity of these hairy root lines 
to synthesize both tropane alkaloids. However, the yields obtained up to now did not reach those of the current scopolamine productive process. Future research could be done considering the higher structural diversity of tropane alkaloids that could be functional to create new metabolic pathways and biological active products. A possible strategy would be cloning and engineering those new metabolic pathways in heterologous organism to produce a chemical structure diversity for generating new compounds with scopolaminelike activity (Harvey, 2000, Butler, 2004, Potterat \& Hamburger, 2008).

\section{Acknowledgment}

This work was supported by Consejo Nacional de Investigaciones Científicas y Técnicas (CONICET) and the Agencia Nacional de Producción Científica y Tecnológica (ANPCyT) (PICT2007 0552).

\section{References}

Ajungla, L., Patil, P.P., Barmukh, R.B. Nikam, T D (2009) Influence of biotic and abiotic elicitors on accumulation of hyoscyamine and scopolamine in root cultures of Datura metel L. Indian J Biotechnol 9: 317-322.

Angelova, Z., Georgiev, S. \& Ross, W. (2006) Elicitation in plants. Biotechnol Eq J 20: 72-83.

Attanassov, I.I., Etchells, J.P. \& Turner, S.R. (2009) A simple, flexible \& efficient PCRfusion/Gateway cloning procedure for gene fusion, site-direct mutagenesis, short sequence insertion \& domain deletions and swaps. Plant Methods 4: 1-11.

Benhamou, N. (1996) Elicitor-induced plant defence pathways. Trends in Plant Sc 1:233-240.

Bulgakov, V.P., Tchernoded, G.K., Mischenko, N.P., Shkryl, Y.N., Fedoreyev, S.A. \& Zhuravlev, Y.N. (2004). The rolB and rolC genes activate synthesis of anthraquinones in Rubia cordifolia cells by mechanism independent of octadecanoid signaling pathway. Plant Sc 166:1069- 1075.

Butler, M.S. (2004) The role of natural product chemistry in drug discovery. J Nat Prod 67: 2141-2153

Canter, P.; Howard, T. \& Edzard, E. (2005) Bringing medicinal plants into cultivation: opportunities and challenges for biotechnology. Trends in Biotechnol 23:180-185.

Cardillo, A.B., Silberstein, S., Giulietti, A.M. \& Marconi, P.L. (2005) Biotransformation of hyoscyamine by a recombinant Saccharomyces cereviciae strain. 2nd Mercosur Congress on Chemical Engineering 4th Mercosur Congress on Process Systems Engineering, Brasil.

Cardillo, A.B., Rodriguez Talou, J. \& Giulietti, A.M. (2008) Expression of Brugmansia candida Hyoscyamine 6beta-Hydroxylase gene in Saccharomyces cerevisiae and its potential use as biocatalyst. Microbial Cell Factories 7: 1-7.

Chunxian, Y., Min, Ch, Lingjiang, Z., Lei, Z., Xiaoqiang, L., Xiaozhong, L., Kexuan, T. \& Zhihua, L. (2011) Improvement of tropane alkaloids production in hairy root cultures of Atropa belladonna by overexpressing pmt and $h 6 h$ genes. Plant Omics J 4: 29-33.

Dubin, M.J., Bowler, C. \& Benvenuto, G. (2008) A modified gateway cloning strategy for overexpressing tagged proteins in plants. Plant Methods 4: 1-11.

Hamill J.D., Parr A.J., Rhodes H.J.C., Robbins R.J., Walton N.J. (1987) New routes to plant secondary products. Biotechnology, p. 800-804. 
Guo, Z. J., Lamb, C. \& Dixon, R. (1997) Release and biological activity of diffusible signal compounds from elicited plant cells. J Plant Physiol 151: 699-710.

Goossens, A., Ha, S.T., Into, L. K. , Seppa, T., nen-Laakso, S.B., De Sutter, V., Lammertyn, F., Nuutila, A.M., So derlund, S., Zabeau, M., Inze, D. \& Oksman-Caldentey, K-M (2002) A functional genomics approach toward the understanding of secondary metabolism in plant cells. Proc Natl Acad Sc 14: 8595-8600.

Goossens, A. \& Rischer, H. (2007) Implementation of functional genomics for gene discovery in alkaloid producing plants. Phytochem Reviews 6: 35-49.

Hakkinen, S.T., Moyano, E., Cusido, M.R., Palazon, J., Teresa Pinol, M. \& OksmanCaldentey, K-M (2005) Enhanced secretion of tropane alkaloids in Nicotiana tabacum hairy roots expressing heterologous hyoscyamine-6b-hydroxylase. J Experimental Botany 56: 2611-2618.

Harvey, A. (2000) Strategies for discovering drugs from previously unexplored natural products. Drug Discov Technol 5: 294-300.

Hashimoto, T. \& Yamada, Y. (1986) Hyoscyamnine6- $\beta$ hydroxylase, a 2 oxaglutarate dependent oxygenase, in alkaloid production root cultures. Plan Physiol 81: 619-625.

Hashimoto, T. \& Yamada, Y. (1987) Purification and characterization of hyoscyamine $6 \beta$ hydroxylase from root culture of Hyoscyamus niger L. Eur J Biochem 194: 277 - 285.

Hashimoto, T, Yukumine, Y. \& Yamda, Y (1989) Putrescine and putrescine Nmethylransferase in the biosynthesis of tropane alkaloids in culture roots of Hyoscyamus albus. Planta 178: 131-137

Hashimoto, T., Hayashi, A., Amano, Y., Kohno, J., Iwanari, H., Usuda, S. \&, Yamada, Y. (1991) Hyoscyamine 6 beta-hydroxylase, an enzyme involved in tropane alkaloid biosynthesis, is localized at the pericycle of the root. J Biol Chem 5: 4648-53.

Hashimoto, T., Yun, D.J. \& Yamada, Y. (1993) Production of tropane alkaloids in genetically engineered root cultures. Phytochem 32 713-718.

Hashimoto, T., Matsuda, J. \& Yamada, Y. (1993) Two-step epoxidation of hyoscyamine to scopolamine is catalyzed by bifunctional hyoscyamine 6-hydroxylase. FEBS Lett 329: 35-39.

Hibi, N., Higashiguchi, S., Hashimoto, T. \&, Yamada, Y. (1994) Gene expression in tobacco low-nicotine mutants. Plant Cell 6: 723-735.

Jouhikainen, K., Lindgren, L., Jokelainen, T., Hiltunen, R., Teeri, T.H. \& Oksman-Caldentey, K-M. (1999) Enhancement of scopolamine production in Hyoscyamus muticus L. hairy root cultures by genetic engineering. Planta 208, 545-551.

Jung, H, Kang, S, Kang, M., Bahn, J, Yang, J. \& Choi M. (2003) Enhanced production of scopolamine by bacterial elicitors in adventitious hairy root cultures of Scopolia parviflora. Enzyme Microb Technol 33: 987-900.

Karimi, M., Inzé, D. \& Depicker, A. (2002) GATEWAY-vectors for Agrobacterium-mediated plant transformation. Trends Plant Sc 7: 193-195.

Kinghorn, A. D. \& Seo, E. K. (1996) Plants as sources of drugs. Agricultural Materials as Renewable Resources 647: 179-193.

Kutty, P.C., Parveez, G.K.A. \& Huyop, F. (2011) Agrobacterium tumefaciens infection strategies for greater transgenic recovery in Nicotiana tabacum cv. TAPM26. I. J Agricultural Research 6: 119-133.

Lawrence, C.B., Singh, N.P., Giu, J.S., Gardener, R.G. \& Tuzun, S. (2000) Constitutive hydrolytic enzymes are associated with polygenic resistance of tomato to Alternaria 
solani and may function as an elicitor release mechanism. Physiol Molec Plant Pathol 57: 211-220.

Liu, X., Yang, C., Chen, M., Li, M., Liao, Z. \& Tang, K. (2010) Promoting scopolamine accumulation in transgenic plants of Atropa belladonna generated from hairy roots with over expression of pmt and h6h gene. J Medicinal Plants Res 4: 1708-1713.

Marconi, P.L., Alvarez, M.A., \& Pitta-Alvarez, S.I. (2006) How polyamine synthesis inhibitors and cinnamic acid affect tropane alkaloid production. Applied Biochem Biotechnol 136: 63-76.

Marconi, P.L., Setten, L., Cálcena, E., Alvarez, M.A. \& Pitta Alvarez, S.I. (2008) Changes in growth and tropane alkaloid production in long-term culture of hairy roots of Brugmansia candida. J Integrative Biosc 3: 38-44.

Matsuda, J., Okabe, S., Hashimoto, T., \& Yamada, Y. (1991) Molecular cloning of hyoscyamine 6B-hydroxylase, a 2-Oxoglutarate-dependent dioxygenase, from Cultured Roots of Hyoscyamus niger. J Biol Chem 266: 9460-9464.

Matzke, A.J.M. \& Matzke, M.A. (1998) Position effects and epigenetic silencing of plant transgenes. Current Opinion in Plant Biol $1: 142-148$

Mizusaki, S., Tanabe, Y., Noguchi, M. \& Tamaki, E. (1973) Changes in the activities of ornithine decarboxylase, putrescine $\mathrm{N}$-methyltransferase and $\mathrm{N}$-methylputrescine oxidase in tobacco roots in relation to nicotine biosynthesis. Plant Cell Physiol 14: 103-110.

Moyano E, Fornale A.S., Palazon J., Cusido R.M., Bonoll M, Morales C. \& Piñol M.T. (1999) Effect of Agrobacterium rhizogenes T-DNA on alkaloid production in Solanaceae plants. Phytochem 52, 1287-1292.

Moyano, E, Fornale, A.S., Palazón, J., Cusido, R.M., Bagni, N. \& Piñol, M.T. (2002) Alkaloid production in Duboisia hybrid hairy root cultures overexpressing the pmt gene.Phytochem 59, 697-702.

Moyano, E., Jouhikainen, K., Tammela, P., Palazón, J., Cusido, R.M., Piñol, M.T., Teeri H.T. \& Oksman-Caldentey K-M. (2003) Effect of pmt gene overexpression on tropane alkaloid production in transformed root cultures of Datura metel and Hyoscyamus muticus. J Exp Botany 54: 203-211.

Oksman-Caldentey, K-M. \& Strauss, A. (1986) Somaclonal variation of scopolamine content in protoplast-derived cell culture clones of Hyoscyamus muticus. Planta Medica 52, 612.

Oksman-Caldentey, K-M., Vuorela, H, Strauss, A. \& Hiltunen, R. (1987) Variation in the tropane alkaloid content of Hyoscyamus muticus plants and cell culture clones. Planta Medica 53, 349-354.

Oksman-Caldentey, K-M., KivelaÈ, O. \& Hiltunen, R. (1991) Spontaneous shoot organogenesis and plant regeneration from hairy root cultures of Hyoscyamus muticus. Plant Science 78,129-136.

Oksman-Caldentey, K-.M. \& Arroo, R. (2000) Regulation of tropane alkaloid metabolism in plants and plant cell cultures, in: R. Verpoorte, A.W. Alfermann (Eds.), Metabolic Engineering of Plant Secondary Metabolism, Kluwer Academic Publishers, Dordrecht, 2000, pp. 253-281.

Oksman-Caldentey, K.M. \& Inze, D. (2004) Plant cell factories in the post-genomic era: new ways to produce designer secondary metabolites. Trends Plant Sc 9: 433-440. 
Oksman-Caldentey, K.M., Häkkinen, S.T. \& Rischer, H. (2007) Chapter 4: Metabolic Engineering of the Alkaloid Biosynthesis in Plants: Functional Genomics Approaches in: Applications of Plant Metabolic Engineering. Veerporte R., Alfermann, A.W., Johnson, T.S. Eds. Springer Netherlands, pp. 109-124.

Palazón, J., Altabella, T., Cusido, R.M., Ribo, M. \& Piñol, M.T. (1995) Growth and tropane alkaloid production in Agrobacterium transformed roots and derived callus of Datura. Biologia Plantarum 37, 161-168.

Palazón, J., Cusidó, R.M., Roig, C. \& Piñol, M.T. (1998) Expression of the rolC gene and nicotine production in transgenic roots and their regenerated plants. Plant Cell Rep 17: 384-390.

Palazón, J., Moyano, E, Cusidó, R.M., Bonfill, M., Oksman-Caldentey, K-M \& Piñol, M.T. (2003) Alkaloid production in Duboisia hybrid hairy roots and plants overexpressing the $h 6 h$ gene. Plant Sc 165: 1289-1295.

Palazón, J, Navarro-Ocaña, A., Hernandez-Vazquez, L. \& Hossein Mirjalili, M. (2008) Application of metabolic engineering to the production of scopolamine. Molecules 13: $1722-1742$.

Pitta Alvarez, S.I. \& Giulietti, A.M. (1997) Effect of gibberellin GA7 on kinetics of growth and tropane alkaloid accumulation in hairy roots of Brugmansia candida. In VitroPlant. , 33:147 - 153.

Pitta Alvarez, S.I., Spollansky, T.C. \& Giulietti, A.M. (2000) Scpolamine and hyoscyamine production by hairy root cultures of Brugmansia candida: influence of calcium chloride, hemicelullase and theophylline. Biotechnol Lett 22: 1653-1656.

Pitta Alvarez, S.I., Marconi, P.L. \& Giulietti, A. (2003) Comparison of the influence of different elicitors of hyosciamine and scopolamine content in hairy roots cultures of Brugmansia candida. In Vitro-Plant, 36: 640-644.

Potterat, O. \& Hamburger, M. (2008) Drug discovery and development with plant-derived compounds. In: progress in drug research, Vol. 65. Eds: F. Petersen \& R. Amstutz. Birkhauser Verlag, Basel, Switzerland. pp. 45-118.

Prakash Rout, S., Choudary, K.A., Kar, D.M., Das. L. \& Jain, A. (2009) Plants in traditional medical system- future source of new drugs. I J Pharmacy Pharmac Sc 1: 1-23.

Qurishi, Y., Hamid, A., Zargar, M.A., Singh, S.K. \& Saxena, A.K. (2010) Potential role of natural molecules in health and disease: Importance of boswellic acid. J Medicinal Plants Res 4: 2778-2785.

Sato, F., Hashimoto, T., Hachiya, A., Tamura, K., Choi, K., Morishige, T., Fujimoto, H. \& Yamada, Y. (2001) Metabolic engineering of plant alkaloid biosynthesis. Proc Natl Acad Sci 98: 367-372.

Shinjiro, O.; Uefuji, H., Masayki, M. \& Hiroshi, S. (2005) Metabolic engineering of caffeine production. Plant Biotechnol 22: 461-468.

Stenzel, O., Teuber, M. \& Drager, B. (2006) Putrescine N-methyltransferase in Solanum tuberosum L., a calystegine-forming plant. Planta 223: 200-212.

Suzuki, K.; Yun, D.-J.; Chen, X.Y.; Yamada, Y. \& Hashimoto, T. (1999) An Atropa belladona hyoscyamine $6 \beta$-hydroxylase gene is differentially expressed in the root pericycle and anthers. Plant Mol Biol 40: 141-152.

Theiss, C., Bohley, P. \& Voigt, J. (2002) Regulation by polyamines of ornithine decarboxylase activity and cell division in the unicellular green alga Chlamydomonas reinhardtii. Plant Physiol 128: 1470. 
Tytgat, G.L. (2007) Hyoscine Butylbromide: A Review of its Use in the Treatment of Abdominal Cramping and Pain. Drugs 67: 1343-1357

$\mathrm{Xu}$, R. \& Quinn, Q.Q. (2008) Protocol: Streamline cloning of genes into binary vectors in Agrobacterium via the Gateway ${ }^{\circledR}$ TOPO vector system. Plant Methods 8: 1-7.

Zabetakis, I., Edwards, R. \& O’Hagan, D. (1998) Elicitation of tropane alkaloid biosynthesis in transformed root cultures of Datura stramonium. Phytochem 50:53-56.

Zhang, L., Ding, R., Chai, Y., Bonfill, M., Moyano, E., Oksman-Caldentey, K-M., Xu, T., Pi, Y., Wang, Z., Zhang, H., Kai, G., Liao, Z., Sun, X., \& Tang, K. (2004) Engineering tropane biosynthetic pathway in Hyoscyamus niger hairy root cultures. Proc Natl Acad Sci 101: 6786-6791. 


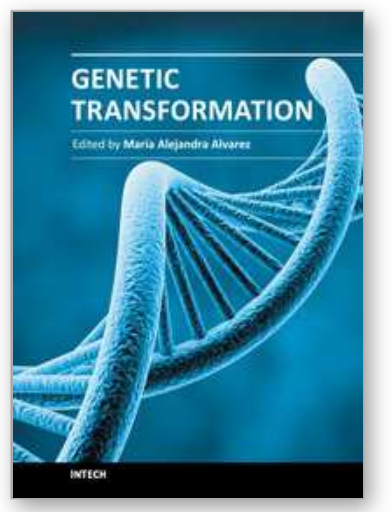

\author{
Genetic Transformation \\ Edited by Prof. MarÃa Alvarez
}

ISBN 978-953-307-364-4

Hard cover, 328 pages

Publisher InTech

Published online 06, September, 2011

Published in print edition September, 2011

Genetic transformation of plants has revolutionized both basic and applied plant research. Plant molecular biology and physiology benefit from this power fool, as well as biotechnology. This book is a review of some of the most significant achievements that plant transformation has brought to the fields of Agrobacterium biology, crop improvement and, flower, fruit and tree amelioration. Also, it examines their impact on molecular farming, phytoremediation and RNAi tools.

\title{
How to reference
}

In order to correctly reference this scholarly work, feel free to copy and paste the following:

María Alejandra Alvarez and Patricia L. Marconi (2011). Genetic Transformation for Metabolic Engineering of Tropane Alkaloids, Genetic Transformation, Prof. MarÃa Alvarez (Ed.), ISBN: 978-953-307-364-4, InTech, Available from: http:/www.intechopen.com/books/genetic-transformation/genetic-transformation-for-metabolicengineering-of-tropane-alkaloids

\section{INTECH}

open science | open minds

\section{InTech Europe}

University Campus STeP Ri

Slavka Krautzeka 83/A

51000 Rijeka, Croatia

Phone: +385 (51) 770447

Fax: +385 (51) 686166

www.intechopen.com

\section{InTech China}

Unit 405, Office Block, Hotel Equatorial Shanghai

No.65, Yan An Road (West), Shanghai, 200040, China

中国上海市延安西路65号上海国际贵都大饭店办公楼405单元

Phone: +86-21-62489820

Fax: +86-21-62489821 
(C) 2011 The Author(s). Licensee IntechOpen. This chapter is distributed under the terms of the Creative Commons Attribution-NonCommercialShareAlike-3.0 License, which permits use, distribution and reproduction for non-commercial purposes, provided the original is properly cited and derivative works building on this content are distributed under the same license. 